Gladys Adelaida Torres

http://dx.doi.org/10.35381/racji.v4i7.353

\title{
Una gerencia otra desde la Comuna a la Educación
}

\section{Another management from the community to education}

\author{
Gladys Adelaida Torres \\ adelaidat0@gmail.com \\ Universidad Bolivariana de Venezuela \\ Venezuela \\ https://orcid.org/0000-0003-3647-8279
}

Recibido: 07 de mayo de 2019

Aprobado: 07 de junio de 2019

\section{RESUMEN}

El Estado es el principal gestor de políticas públicas y está a cargo de la administración de los recursos para satisfacer necesidades colectivas, por ello el modelo que asuma para regir los destinos del país condicionara sus funciones, la educación es una de ellas y su labor primordial ha sido reproducir saberes y prácticas administrativas impuestos desde siglos atrás por el sistema de dominación neoliberal hegemónico. En este artículo se reflexiona si la gerencia moderna es la respuesta como se declara en los últimos tiempos y la analiza desde una mirada decolonial, la contextualiza ideológica e históricamente para luego situarla en la transmodernidad. En Venezuela, la propuesta constituyente del Estado Comunal tiene como célula fundamental la comuna, se trata de repensar la realidad de la gestion educativa desde esta lógica comunitaria desde la solidaridad para romper el pensamiento único colonial y en un ejercicio de pluralidad, plantear alternativas para descolonizar la gerencia de las políticas públicas en la educación.

Descriptores: Estado; Gestión educacional; Colonialismo; Comunidad.

\section{SUMMARY}

The State is the main manager of public policies and is in charge of the administration of resources to meet collective needs, therefore the model that assumes to govern the destinies of the country will condition its functions, education is one of them and its primary task It has been reproducing knowledge and administrative practices imposed since centuries ago by the system of hegemonic neoliberal domination. This article reflects on whether modern management is the answer as stated in recent times and analyzes it from a decolonial perspective, contextualizes it ideologically and historically and then situates it in transmodernity. In Venezuela, the constituent proposal of the Communal State has as its fundamental cell the commune, it is about rethinking the 


\section{Revista Arbitrada Interdisciplinaria KOINONIA \\ Año IV. Vol IV. N8. Julio - Diciembre 2019 \\ Hecho el depósito de Ley: FA2016000010 \\ ISSN: 2542-3088 \\ FUNDACIÓN KOINONIA (F.K). Santa Ana de Coro. Venezuela. \\ Gladys Adelaida Torres}

reality of the educational management from this community logic from solidarity to break the colonial sole thought and in an exercise of plurality, to propose alternatives to decolonize the management of public policies in education.

Descriptors: State; Educational management; Colonialism; Community.

\section{A MODO DE INTRODUCCIÓN}

La gerencia educativa requiere revisar su trasfondo ideológico, esto no es más que revisar el contexto en el cual se desarrolla y los condicionantes a las que se ha sometido a través de tiempo. Aunque es una práctica muy novedosa desde las décadas de los años 80 y 90 del siglo XX, está marcada por el devenir de las ideas de la administración en general de los recursos colectivos.

Desde los inicios el hombre ha desarrollado mecanismos para satisfacer sus necesidades, que se inician desde procesos muy simples, pero siempre implican organización, para trazar objetivos, realizar diagnósticos de la situación inicial, planificar actividades y ejecutarlas.

En sociedades pequeñas era una organización tribal, comunitaria se repartían las actividades de manera consuetudinaria bajo la figura de un líder que se distinguía por sus cualidades o fuerza y de acuerdo a las necesidades comunes. El mundo se complejizo y al adquirir niveles jerárquicos de organización, con la división social del trabajo, la propiedad privada y las clases sociales, surge además de las organizaciones de capital e interés privado, un elemento de orden que es el Estado en sus diferentes formas históricas.

De allí que la administración y las políticas públicas van a estar condicionadas por el modelo político de Estado dentro del cual se dicten. En el modelo absolutista la autoridad se concentra y confluyen en una misma persona el poder económico, religioso, militar, político e ideológico. La actividad primordial a gestionar es la económica y siempre va a ser esta dimensión la que determine las formas del hacer administrativo, predominaba la gestión de la tierra y en este modo de producción la figura central era el monarca que concentraba todo el poder, que regulaba la actividad de los feudos a través de los impuestos y el reparto de propiedades y títulos. 


\section{Revista Arbitrada Interdisciplinaria KOINONIA \\ Año IV. Vol IV. N8. Julio - Diciembre 2019 \\ Hecho el depósito de Ley: FA2016000010 \\ ISSN: 2542-3088 \\ FUNDACIÓN KOINONIA (F.K). Santa Ana de Coro. Venezuela. \\ Gladys Adelaida Torres}

De allí en adelante, se da un salto que desde la corriente de pensamiento conocida como los contractualistas, explica que el Estado surge como expresión de un acuerdo para convivir, Hobbes (1588-1679), en su Leviathan afirma que los hombres se hallaban en un perenne conflicto y necesitaban un orden que les permitiría llegar a acuerdos pactados para mantener la paz, se refería a la figura del monarca como ente centralizador y capaz de mantener el orden.

Mas adelante John Locke (1632-1704), en su Tratado sobre del Gobierno Civil plantearía que los hombres vivían en paz en su estado de naturaleza sin embargo cuando veían afectados sus bienes o derechos personales donde se privilegia la propiedad privada de forma casi absoluta, entraban en conflicto. y necesitaban un árbitro para su resolución, el máximo poder era el parlamento votado por la comunidad para que legisle y dicte políticas a seguir para el bien de todos.

Complementada por las ideas del Contrato Social de Rousseau (1712-1778), pacto que se celebra para que reine la voluntad general sobre la individual, procurando un nuevo Estado con bondad y felicidad; y la división de poderes de Montesquieu (1689-1755) separando funciones ejecutivas, legislativas y judiciales, durante el periodo conocido como Siglo de las Luces.

Por su parte Hume (1711-1776) a diferencia de Hobbes afirma que los hombres se interesan por lo más cercano, por satisfacer sus intereses egoístas y se unen para evitar problemas con la propiedad y la economía, por ello expresa citado por (Castro, 2005:29):

la ciencia del hombre establece que en el origen de la sociedad humana se encuentra la creación de un mecanismo regulador de la economía, cuya función es permitir que los individuos satisfagan sus necesidades naturales, pero sólo hasta el punto de no perjudicar lo que todos valoran como interés público: la autoconservación. La ley del Estado debe dar prioridad a lo remoto, con el fin de que todos puedan optar por lo cercano.

Idea compartida y desarrollada luego por su discípulo Adam Smith (1723-1790) en el libro la Riqueza de las Naciones, quien considera que no se debe regular la conducta económica por normas, sino que se debe dejar hacer y serán las propias leyes de la 


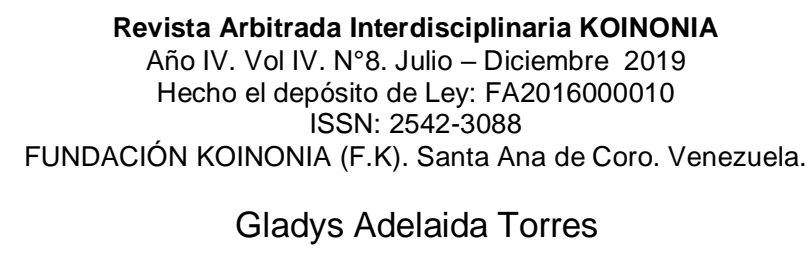

naturaleza que la regulen en un mecanismo natural, el mercado, que regula el intercambio de las mercancías como mano invisible y logra el equilibrio entre lo individual y lo colectivo. (Castro, ob.cit :30).

Dichas ideas serian cuestionadas más adelante por pensadores como Karl Marx (18181883) y Federico Engels (1820-1895) que plantearían la existencia y aparición del Estado como producto de la lucha de clases existente en la sociedad, a través de él se legitima una situación de opresión de una clase más poderosa propietaria de los medios de producción sobre otra la clase asalariada explotada obligada a vender su fuerza de trabajo, que es la que produce valor o riqueza.

Todo este bagaje se impuso en nuestra realidad en 1492 cuando Abya Yala ingresa al sistema mundo moderno colonial, como bien lo ilustra (Quijano ,2000: 201):

La globalización en curso es...la culminación de un proceso que comenzó con la constitución de América y la del capitalismo colonial/moderno y eurocentrado como un nuevo patrón de poder mundial; uno de los ejes fundamentales de este patrón de poder es la clasificación social de la población mundial sobre la idea de raza, una construcción mental que expresa la experiencia...de la dominación colonial y...permea las dimensiones más importantes del poder mundial, incluyendo su racionalidad específica, el eurocentrismo.

Se configura el patrón de dominación de la colonialidad del poder, del saber y del ser, siendo la primera la estructura hegemónica que clasifica desde las diferencias a las personas por raza, trabajo, sexo, cultura y espacio al servicio del capital, con el engaño de lograr el desarrollo; en el saber se impone la visión del mundo desde la mirada del colonizador, subalternizando e ignorando culturas y saberes originarios, se explica el mundo desde lo universal, objetivo y neutral , que (Castro,2005) llama la Hybris del punto cero. Y la colonialidad del ser es la dimensión ontológica de la colonialidad que se afirma en la violencia de la negación del Otro. (Maldonado, 2007), con ella se naturaliza la esclavitud, la servidumbre, el exterminio, la guerra contra los inferiores.

Bajo esta concepción se configura toda la institucional surgida en este territorio americano, Venezuela estructura su organización educativa con un enfoque eurocéntrico alejado de nuestra realidad. Por ello es necesario como invita de (De 


\section{Revista Arbitrada Interdisciplinaria KOINONIA \\ Año IV. Vol IV. N8. Julio - Diciembre 2019 \\ Hecho el depósito de Ley: FA2016000010 \\ ISSN: 2542-3088 \\ FUNDACIÓN KOINONIA (F.K). Santa Ana de Coro. Venezuela. \\ Gladys Adelaida Torres}

Souza Silva ,2011:8) a soñar e imaginar la sociedad y la educación que queremos el día después del desarrollo y así sustituirlas por "los 'proyectos de vida', de 'comunicación para la vida' y de 'educación para la vida'. El "desarrollo como meta universal” es reemplazado por el 'buen vivir', el 'vivir bien', el 'ser feliz' como fin".

Apostar por la defensa de la diversidad, por el pluralismo como afirman (Contreras y Calles, 2016:58).

El pluralismo supone el reconocimiento de la diversidad cultural, y por lo tanto, una nueva mirada a la construcción del conocimiento, en este nuevo enfoque se parte de la identificación y la visualización de lo particular, sin pretensión alguna de universalizar, la riqueza de la cultura humana identificada en el estatuto de la ciencia por sí misma.

Construir un proyecto de vida donde la educación como proceso sea además de un derecho, un servicio pensado y organizado para todos.

\section{Política pública y gerencia moderna.}

La política pública según (Parsons, 2007:47) "representa el intento de definir y estructurar una base racional para actuar o no actuar.".

Bacon la identifico con astucia racional, Weber con la burocracia, Keynes piensa que no trata asuntos relacionados con la política, sino que sería lo económico lo que determinaría la toma de decisiones. En los años 50 y principios de los 60 del siglo XX recibió aportes de la sociología, psicología. Para Laswell citado por (Parsons, ob.cit:51) son las disciplinas que se ocupan de explicar los procesos de formulación y ejecución de políticas, así como de localizar datos y brindar interpretaciones pertinentes a los problemas de las políticas públicas en determinado período. La identifica como ciencia de las políticas públicas.

Durante los periodos de las guerras mundiales sirvieron a la necesidad de formular planes de economía, seguridad y defensa Luego de la segunda guerra mundial, recién pasada la gran depresión de 1929, se da una reorganización de los actores políticos económicos y, EEUU busca mantener su predominio y decide expandir su dominio 


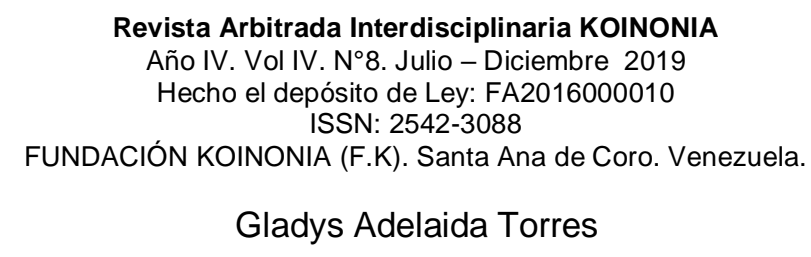

sobre los países del tercer mundo para ello convoca la conferencia de Breton Woods en 1944.

Su idea central era crear una estructura de instituciones internacionales para asegurar su hegemonía bajo la figura de organismos multilaterales EEUU se aseguró su control a través de la política de un dólar un voto. (Saxe,2004).

Así se crea un nuevo orden internacional bajo los principios del libre cambio y la empresa privada, lo que atenta directamente con la noción de Estado nación y soberanía.

Estas acciones son políticas públicas originadas desde el centro de poderes irradiada hacia los periféricos, impactando no solo en lo económico y defensa sino también en lo cultural, así en la educación pública universitaria tanto en la docencia como en la investigación, se impuso de forma más radical así lo que Ramonet llama pensamiento único. (Saxe, ob. Cit.:68).

En ese ataque contra lo cultural se incorporan a la educación imágenes, valores, ideas, costumbres, instituciones, bienes pautas y aspiraciones de consumo, que influyen en la economía., la organización política y la cultura. Se busca como líneas de acción la privatización, desregularización y orientación por el mercado alejando las funciones de la gestión educativa del interés estatal y poniéndola al servicio de las corporaciones nacionales e internacionales. El objetivo preparar profesionales aptos para el mercado alejados de los intereses del Estado y la gestión pública que debe atender las necesidades de la población, se sustituye la imagen del pueblo por la del cliente o consumidor.

el proyecto hegemónico es un proyecto social centrado en la primacía del mercado, de los valores puramente económicos, en los intereses de los grandes grupos industriales y financieros. Los significados privilegiados en ese discurso son: competitividad, flexibilización, ajuste, globalización, privatización, desreglamentación, consumidor, mercado. En ese proyecto, la educación se ve simplemente como un elemento instrumental para alcanzar metas económicas compatibles con tales intereses (Da Silva citado por Vasquez,2013:184). 


\section{Revista Arbitrada Interdisciplinaria KOINONIA \\ Año IV. Vol IV. N8. Julio - Diciembre 2019 \\ Hecho el depósito de Ley: FA2016000010 \\ ISSN: 2542-3088 \\ FUNDACIÓN KOINONIA (F.K). Santa Ana de Coro. Venezuela. \\ Gladys Adelaida Torres}

Dentro de este contexto se intenta la discusión de nuevos paradigmas para las políticas publicas y la gerencia desde diferentes ópticas, teorías del pensamiento complejo, de los juegos, sistémica o del caos. En esta reflexión se prefiere aportar desde la opción decolonial y de transmodernidad de (Dussel:1992) que plantea reconocer la existencia del otro que ha sido invisibilizado por un sistema mundo global, discriminador, donde predomina el hombre, blanco, europeo, propietario y el conocimiento y la ciencia se identifican con el saber eurocéntrico, colonial, universal, tras la falacia de alcanzar el desarrollo y progreso nacional en base a la adopción de un lenguaje y sistema de prácticas homogeneizadoras y hegemónicas, ignorando la pluriversalidad ciudadana e identitaria, ocultando las otras culturas indígenas, negras, mestizas y campesinas, manteniendo la división en desarrollados y subdesarrollados, teniendo como único modelo la sociedad occidental industrializada.

De igual forma difiere de la definición tradicional que identifica modernidad con globalización y plantea que la modernidad toma forma en 1492 luego que América aparece en el horizonte.

Proponemos una segunda visión de la "Modernidad", en un sentido mundial, y consistiría en definir como determinación fundamental del mundo moderno el hecho de ser (sus Estados, ejércitos, economía, filosofía, etc.) "centro" de la Historia Mundial. Es decir, nunca hubo empíricamente Historia Mundial hasta el 1492 (como fecha de iniciación11 del despliegue del "Sistema-mundo"). (Dussel: 1992:10).

Esta noción tiene un contenido secundario y negativo que es la justificación de una praxis irracional de violencia conocida como el mito de la modernidad. para romper lo que advierten (Delgado y Escobar,2007:10):

Entendemos que la lógica homogeneizadora y colonizadora de la ciencia occidental tiene su origen en una combinación de cosmovisiones basadas en el monoteísmo religioso (cristiano, judío y musulmán) con afanes e intereses colonizadores que excluye, si no puede aniquilar, cosmovisiones diferentes; del mismo modo que entiende a la educación como un instrumento de entrenamiento -más que formación- de las nuevas generaciones en la cosmovisión monoteísta y toda la secuela civilizatoria, filosófica, cultural y de sentido común que de ella se deriva. 


\section{Revista Arbitrada Interdisciplinaria KOINONIA \\ Año IV. Vol IV. N`8. Julio - Diciembre 2019 \\ Hecho el depósito de Ley: FA2016000010 \\ ISSN: 2542-3088 \\ FUNDACIÓN KOINONIA (F.K). Santa Ana de Coro. Venezuela. \\ Gladys Adelaida Torres}

La liberación educativa en lo epistémico arropa también a lo gerencial es una ruptura con el discurso hegemónico de dominación desde nuevas practicas que desmitifique todo el proceso civilizatorio impuesto.

\section{Gerencia o gestión educativa y Comuna}

Enfrentar el mito de la modernidad implica dejar de tener como fin de la humanidad la idea de desarrollo y progreso y reconocer que necesitamos reconstruir nuestra relación con la humanidad y con la tierra, recuperar al hombre en su conexión con la naturaleza en convivencia armónica y no solo en explotación de recursos. Afrontar los problemas que Boaventura de Souza (2009:39) nos muestra en esta aseveración:

La promesa de la dominación de la naturaleza y de su uso para el beneficio común de la humanidad, condujo a una explotación excesiva y despreocupada de los recursos naturales, a la catástrofe ecológica, a la amenaza nuclear, a la destrucción de la capa de ozono, y a la emergencia de la biotecnología, de la ingeniería genética y de la consiguiente conversión del cuerpo humano en una mercancía última. La promesa de una paz perpetua, basada en el comercio, en la racionalización científica de los procesos de decisión y de las instituciones, condujo al desarrollo tecnológico de la guerra y al aumento sin precedentes de su poder destructivo. La promesa de una sociedad más justa y libre, sustentada en la creación de riqueza fue hecha posible por la conversión de la ciencia en fuerza productiva, condujo a la expoliación del llamado Tercer Mundo y a un abismo cada vez mayor entre el Norte y el Sur. En el siglo XX murió más gente de hambre que en cualquiera de los siglos anteriores, e, incluso en los países más desarrollados, continúa subiendo el índice de los socialmente excluidos, aquellos que viven por debajo del nivel de pobreza (el llamado "Tercer Mundo Interior).

Se hace imperioso construir una nueva cosmovisión de lo necesario para afrontar los problemas actuales de la humanidad. Una de las grandes ausencias de las que nos habla Hinkerlammert (2007:14) es la del ser humano en las relaciones sociales:

Por eso la recuperación de lo humano es y tiene que incluir la humanización de la relación humana con la naturaleza. No se puede derivar nada de la naturaleza como tal, no puede haber derechos naturales o de la naturaleza de por sí. La exigencia de la humanización resulta de las relaciones entre los seres humanos y de ellos con la 


\section{Revista Arbitrada Interdisciplinaria KOINONIA \\ Año IV. Vol IV. N`8. Julio - Diciembre 2019 \\ Hecho el depósito de Ley: FA2016000010 \\ ISSN: 2542-3088 \\ FUNDACIÓN KOINONIA (F.K). Santa Ana de Coro. Venezuela. \\ Gladys Adelaida Torres}

naturaleza externa, es la exigencia de hacer presente aquello, que está presente por ausencia en estas relaciones.

La propuesta de la patria venezolana, tan agredida en la actualidad, es la irrupción del Estado democrático y social derecho y de justicia con base fundante en la comuna expresión del poder constituyente originario, en virtud de lo cual cualquier gestión pública se encamina a oír, conocer las necesidades que se padecen en este núcleo primario para en conjunto afrontar y delinear las actividades para conseguir los objetivos colectivos.

Para lograr ese objetivo tal como lo contempla la Constitución de la República Bolivariana de Venezuela (CRBV), la educación es uno de los procesos para conseguir los fines del Estado (art 3), por ello está íntimamente ligada en la generación de políticas públicas que tiendan a materializarlas las aspiraciones de respeto a la dignidad, ejercicio democrático de la voluntad popular, desarrollo de la personalidad, respeto de los derechos humanos, construcción de una sociedad justa y amante de la paz, que busca la promoción de la prosperidad y bienestar del pueblo.

Se le caracteriza como derecho humano y un deber social, lo que implica que a todos ciudadanos debe tener acceso a ella, pero asimismo dentro del principio de corresponsabilidad su ejercicio debe ser garantizado por todos los miembros de la sociedad y por ello, se concibe también como un servicio público que se presta en una sociedad plural y democrática, donde se valora éticamente el trabajo y se promueva la participación activa consciente y solidaria en los procesos de transformación consustanciados con valores de identidad nacional y con una visión latinoamericana y universal (art102 de la CRBV).

Estos dos principios constitucionales van enmarcando lo que debe ser la gestión de la educación en el estado democrático y social, de derecho y de justicia; un servicio público para formar un ciudadano ético, participativo, solidario, con sentido de pertenencia, identidad no solo nacional sino nuestroamericano y universal.

La educación vista dentro de esta nueva cosmovisión, es producto del proceso histórico que desde 1998 vive la nación venezolana, como respuesta a un paradigma 


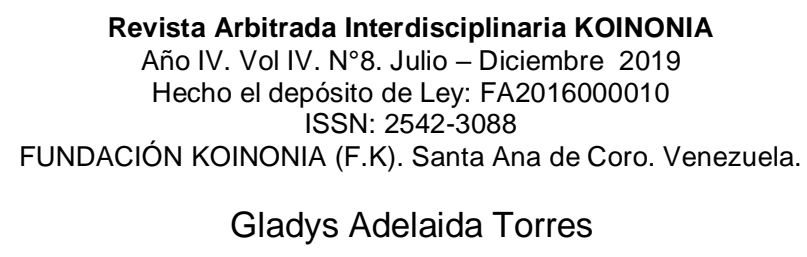

hegemónico neoliberal que hemos heredado desde el momento de la llegada de los europeos a nuestro continente en 1492, cuando avasallaron las culturales ancestrales e impusieron no solo en lo político, sino también sobre el ser y el saber a través del proceso de colonización.

El modelo de educación impuesto fue eurocéntrico y era la expresión de la aplicación del paradigma cartesiano, el cual implicaba la separación del sujeto y conocimiento que produce, cuya finalidad era dominar la naturaleza, fomentando un conocimiento dividido en partes para su estudio.

Para el momento de la conquista y colonización Europa era la expresión de un proyecto que identificado como Cosmópolis donde se trataba de generar un conocimiento de carácter universal aplicable a todo lugar y tiempo, a través del método científico ignorando las particularidades y la historia de los pueblos. "Ubicarse en el punto cero es el comienzo epistemológico absoluto. Equivale a tener el poder de instituir, de representar, de construir una visión sobre el mundo social y natural reconocida como legítima y avalada por el Estado" (Castro, ob.cit.25).

Este paradigma nos ha llevado a un sistema enmarcado en el capitalismo que solo busca la rentabilidad y cuyo principal valor es la propiedad privada de los medios de producción y la generación de ganancias o plusvalía para la acumulación de capital, enmascarando todo con un discurso científico de búsqueda de desarrollo y progreso.

A decir de (De Souza ,2011:11):

La ciencia de Europa occidental fue creada para fundar una nueva visión de mundo. La emergencia de esta ciencia moderna gana energía extra en el siglo XVII con Galileo unificando las nociones de física y matemática y proponiendo la experimentación sobre la naturaleza, con Descartes fundando un conocimiento mecanicista y reduccionista, y con Bacon promoviendo el método experimental y la relación del saber con el poder Apoyados en la razón y la experimentación, los científicos juegan a ser Dios. La naturaleza puede ser controlada cuando expresada matemáticamente en la forma de leyes universales. La ciencia puede descifrar las leyes del funcionamiento de la sociedad y sus instituciones.

Este paradigma ha ocasionado muchas desgracias para el ser humano al degradar la naturaleza por una superexplotación de sus recursos, incrementando la pobreza, la 


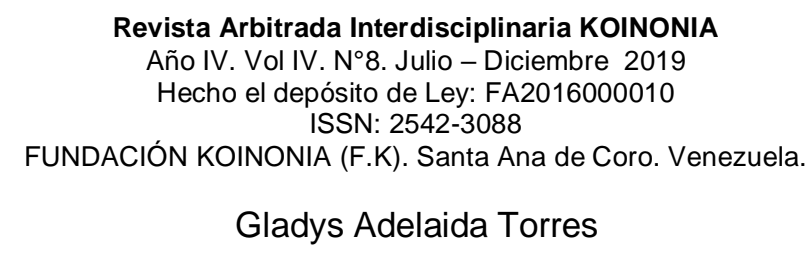

desigualdad y el hambre, por ello se considera agotado y se enrumba en búsqueda de nuevas visiones.

Para este paradigma [clásico de innovación de la ciencia moderna], lo más importante es la acumulación del capital [...] Las promesas de progreso y desarrollo que...guiaron a toda la humanidad, ya mostraron a plenitud sus limitaciones y efectos devastadores, sobre todo en países "altamente desarrollados" como los países europeos, en los que hoy en día, la prioridad ya no es el desarrollo, sino la forma de revertir todo el daño que se ha causado (Huanacuni 2010:18).

Todo eso nos lleva a revisar los fines o principios que deben guiar los cambios de una gestión educativa que se gestó dentro de ese paradigma, por ello no se trata de sustituirlo con un enfoque interdisciplinario o multidisciplinario, se trata de la forja de una nueva cosmovisión que tenga al ser humano como centro, en una relación de armonía con la naturaleza que será lo que garantizara la supervivencia de todos.

Hablar de eficacia, eficiencia, efectividad, productividad, sin enfrentar el marco teoricoideologico- político que en ella subyace no permitirá su transformación. Esa búsqueda basada en el dialogo que trasciende el oír y responder, implica avanzar construyendo conciencia de la realidad y sus múltiples determinaciones para diseñar la escuela, el liceo o la universidad que se quiere o se necesita, lo que incide en el currículo, la docencia y la investigación que se amerita.

Necesita acciones concertadas en el propósito de deconstruir estructuras, prácticas, valores, individualistas que dividen y muestran solo la cara de la colonialidad impuesta. Entre ellas evaluar y desmitificar toda la estructura de dominación. Por ello la nueva gestión debe ser colectiva, horizontal, en constantes dialogo con todos los sectores, tomas de decisiones conjuntas, acuerdos, propuestas y proyectos que expresen el objetivo más allá de lo individual hacia lo comunal.

Situada la institución educativa dentro del territorio de la comuna, su gestión envuelve participar en los planes que se diseñan para la satisfacción de las necesidades comunes, expresados en el plan comunal y ejecutados en proyectos de diversa índole. 


\section{Revista Arbitrada Interdisciplinaria KOINONIA \\ Año IV. Vol IV. N8. Julio - Diciembre 2019 \\ Hecho el depósito de Ley: FA2016000010 \\ ISSN: 2542-3088 \\ FUNDACIÓN KOINONIA (F.K). Santa Ana de Coro. Venezuela. \\ Gladys Adelaida Torres}

Esta nueva gestión educativa busca insertarse dentro de esos planes comunales y coadyuvar a su logro, no solo en un acompañamiento, sino también en su discusión y preparación como política de punto y circulo. La escuela, la universidad debe ir afuera conocer su entorno y la comunidad debe entrar a las instituciones pero no en relación de inquilino o visitantes sino como partes de un todo interrelacionado.

La comuna según la Ley Orgánica de Las comunas (Articulo 5) es:

Es un espacio socialista que, como entidad local, es definida por la integración de comunidades vecinas con una memoria histórica compartida, rasgos culturales, usos y costumbres, que se reconocen en el territorio que ocupan y en las actividades productivas que le sirven de sustento, y sobre el cual ejercen los principios de soberanía y participación protagónica como expresión del Poder Popular, en concordancia con un régimen de producción social y el modelo de desarrollo endógeno y sustentable, contemplado en el Plan de Desarrollo Económico y Social de la Nación.

Seria ella el embrión organizativo del Estado y es una forma de autogobierno y expresión del poder popular. Toda comunidad educativa ya sea pública o privada, como ya se dijo está ubicada en una comuna, su relación con ella la rige la ya citada Ley comunal en su Artículo 3:

Están sujetas a la aplicación de esta Ley, las organizaciones comunitarias, las comunidades organizadas y todas las instancias del Poder Popular debidamente constituidas, así como las personas naturales y jurídicas, tanto de derecho público como privado, que se relacionen con las comunas.

En virtud de ello, resulta lógico concluir que las instituciones educativas no pueden manejarse fuera del ámbito comunal como un ente cerrado, sino que deben interactuar con ella y hacer suyos los principios que la inspiran que son según el artículo 2 de la ley ejusdem:

La constitución, conformación, organización y funcionamiento de la Comuna se inspira en la doctrina del Libertador Simón Bolívar, y se rige por los principios y valores socialistas de participación democrática y protagónica, interés colectivo, complementariedad, diversidad cultural, defensa de los derechos humanos, corresponsabilidad, deber social, cogestión, autogestión, autogobierno, cooperación, solidaridad, 


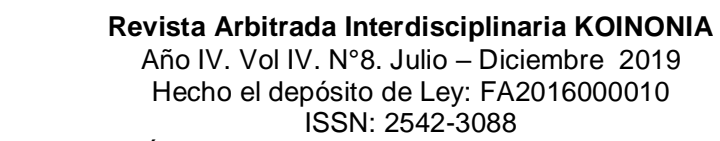

Año IV. Vol IV. N8. Julio - Diciembre 2019

ISSN: 2542-3088

FUNDACIÓN KOINONIA (F.K). Santa Ana de Coro. Venezuela.

Gladys Adelaida Torres

transparencia, honestidad, eficacia, eficiencia, efectividad, universalidad, responsabilidad, rendición de cuentas, control social, libre debate de ideas, voluntariedad, sustentabilidad ambiental, igualdad social y de género, garantía de los derechos de la mujer, de los niños, niñas y adolescentes y de toda persona en situación de vulnerabilidad, de equidad, justicia y defensa de la integridad territorial y la soberanía nacional.

Todos estos valores están inspirados en la CRBV de 1999, dentro de ellos se resaltan para una buena gestión educativa la democracia, participativa y protagónica, la conciencia del deber social, el libre debate de ideas, la defensa de los derechos humanos, la integridad territorial y soberanía nacional.

Dentro de una gestión educativa emancipadora o liberadora, debe estar presente la participación protagónica como elemento fundamental para derrotar el síndrome de la democracia representiva, que creo los directores, rectores, todopoderosos y entender la noción del equipo y de servidores como voceros del poder popular, que están allí para gestionar no su propio interés individual o de grupo sino para coadyuvar a cumplir con los fines de la comunidad donde hace vida la institución y del país en general.

Tal como lo manifiestan (García, García e Isea, 2017:80):

La participación democrática favorece la definición justa de los espacios de contribución y beneficio individual del esfuerzo humano colectivo, la solidaridad y el ejercicio efectivo de la justicia social y la organización social para la autogestión bajo los principios de libertad y equidad.

Espacios colectivos que gestionan la institución con sentido de justicia social no individual, protagonismo de todos organizados con libertad de proponer y decidir.

Otra noción importante que se incorpora es el deber social que avanza más allá de resolver los problemas de forma individual y se trata como ya hemos dicho antes de restablecer la humanidad del ser humano con sus semejantes y con la naturaleza y derrotar el egoísmo, en palabras de (Aponte, 2008):

...es la conciencia de la pertenencia a la sociedad, el convencimiento de que la suerte de la sociedad depende del esfuerzo de cada uno de sus hijos, y que la suerte de cada uno de los individuos depende de la suerte de la sociedad toda, la certeza de la imposibilidad de las salidas 


\section{Revista Arbitrada Interdisciplinaria KOINONIA \\ Año IV. Vol IV. N`8. Julio - Diciembre 2019 \\ Hecho el depósito de Ley: FA2016000010 \\ ISSN: 2542-3088 \\ FUNDACIÓN KOINONIA (F.K). Santa Ana de Coro. Venezuela. \\ Gladys Adelaida Torres}

individuales a los grandes problemas sociales. Se establece así la sociedad del amor

Esa conciencia del deber social expresada en la gestión educativa, significa deconstruir toda la idea de gerencia basada en un liderazgo único con una lista seguidores adeptos., hacia la construcción de una organización que busque aprovechar las mejores cualidades, talentos conocimientos de cada una de sus integrantes en un trabajo colectivo, que implicara cambios y relevos en el equipo de vanguardia cada vez que la situación lo exija.

Serán los objetivos a perseguir y las situaciones que se presenten las que determine como funciona ese colectivo que conducirá la gestión de la institución, lo que no niega que exista un responsable coordinador para guiar los procesos, pero con una consigna diferente la conciencia del deber social.

El libre debate de ideas, implica la dialogicidad en su amplia expresión donde se piensan, se reflexionan y se construyen las ideas, proyectos en colectivo. Asimismo, la defensa de los derechos humanos es guía de todas las acciones que se emprenden por ser un fin del Estado, ello permite la inclusión, la protección de los más vulnerables, el respeto a la interculturalidad, lo que augura una mejor convivencia y paz.

Por último, todas las instituciones que funcionen dentro del territorio deben coadyuvar a cumplir los fines del Estado, ante el ataque del sistema capitalista neoliberal globalizado o imperialismo, que como ya se ha dicho ha ocasionado grandes problemas económicos sociales, ambientales, la defensa del Estado nación, en su acepción de patria como ente soberano, es tarea prioritaria y resulta primordial reconocer pertenecer, apreciar y fomentar el amor patriótico.. Ello permitirá entender cómo funcionan los entes corporativos internacionales a los que se enfrenta y como se requiere fortalecer la venezolanidad, porque solo desde un país fuerte culturalmente, se puede construir un país potencia que pueda relacionarse en igualdad, respeto con los demás países del mundo. 


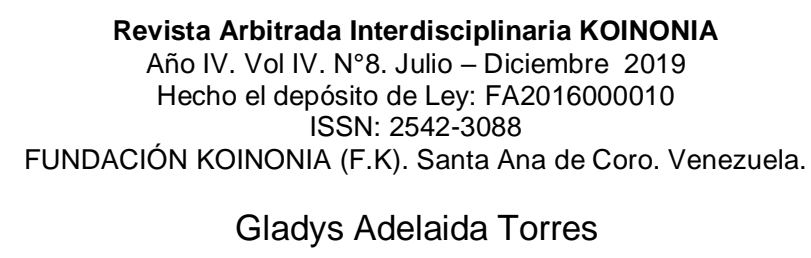

\section{REFLEXIÓN FINAL}

La superación de la colonialidad como estado de dominación del poder, del saber y del ser, solo se consigue con la forja de un pensamiento crítico, que devele toda la mentira escondida en el paradigma hegemónico occidental impuesto.

Pensarnos a nosotros mismos, rencontrarnos al vencer las ausencias de que habla Hinkerlammert, sobretodo la del ser humano disfrazado como consumidor, comprador, productor, trabajador, es tarea pendiente.

La gerencia moderna del mercado no aplica para cumplir los fines del Estado Comunal que debe insurgir, debe ser una gestión humana que apueste al logro de la máxima felicidad posible, al buen vivir, a la vida.

La actuación de las instituciones educativas es crucial pues es la encargada de coadyuvar a elevar conciencias y esto solo lo pueden hacer los que se reconocen libres e independientes, pero no para reprimir a otros sino para convivir con otros.

La expresión de los zapatistas un mundo donde quepan muchos mundos es el argumento final lograr en estos momentos entrelazar experiencias de luchas alternativas, generar un pluriverso donde varios mundos convivan en paz, con respeto y dignidad en igualdad, sin seres superiores e inferiores, sin explotación de muchos por parte de pocos. No más gerencias basadas en la competitividad, en ganancias capitalistas; sí, más gestión humana en armonía con el cosmos. Más vida...

\section{REFERENCIAS CONSULTADAS}

1. Aponte, A (2008) . Blospot Un grano de maíz de fecha 27 de febrero de 2008.Disponible en http://ungranodemaiz.blogspot.com/2008/02/conciencia-deldeber-social.html

2. Asamblea Nacional (1999). Constitución de la República Bolivariana de Venezuela. Gaceta Oficial de la República Bolivariana de Venezuela, 36.860, diciembre 30.

3. Asamblea Nacional (2010). Ley Orgánica de Las Comunas. Gaceta Oficial de la República Bolivariana de Venezuela No 6.011, en fecha 21 de diciembre de 2010, 


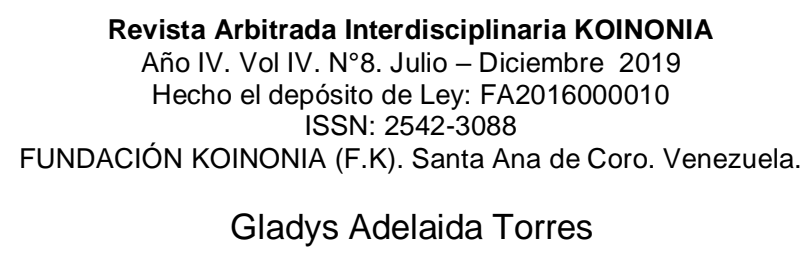

4. Castro Gómez (2005). La Hybris del punto cero. Ciencia, raza e ilustración en la Nueva Granada. (1750-1816). Pontificia Universidad Javeriana. Bogotá.

5. Contreras S y Calles, J. (2016). Justicia otra desde la diversidad cultural y el poder popular emergente. En lustitia Socialies. Revista Arbitrada de Ciencias Jurídicas. Santa Ana de Coro. Venezuela. Disponible en http://fundacionkoinonia.com.ve/ojs/index.php/lustitia Socialis/article/view/28/19

6. De Souza, J. (2011). Hacia el "día después del desarrollo". Pontificia Universidad de Ecuador.

7. García, L., García, J e Isea, J. (2017). Aportes de la nueva ciencia al pensamiento científico en el área gerencial. Revista Arbitrada Interdisciplinaria Koinonía, 1(1), 76-87. Santa Ana de Coro. Venezuela. Disponible en http://fundacionkoinonia.com.ve/ojs/index.php/revistakoinonia/article/view/16

8. Hinkerlammert, F. (2008). Sobre la reconstitución del pensamiento crítico. En Revista Polis vol. 7 no 21, 2008 prólogo, págs., 367-395. Editorial de la Universidad Bolivariana de Chile.

9. Huanacuni, F. (2010). Paradigma Occidental y Paradigma Indígena Originario. En América Latina en movimiento, febrero 2010, № 452, pp. 17-22.

10.Maldonado, N. (2007). Sobre la colonialidad del ser, contribuciones al desarrollo de un concepto. En El giro decolonial: Reflexiones para una diversidad epistémica más allá del capitalismo global / compiladores Santiago CastroGómez y Ramón Grosfoguel. Siglo del Hombre Editores; Universidad Central, Instituto de Estudios Sociales Contemporáneos y Pontificia Universidad Javeriana, Instituto Pensar. Bogotá.

11.Parsons, W. (2007). Políticas Públicas, Una introducción a la teoría y la práctica del análisis de las políticas públicas. Flacso. México.

12. Quijano, Aníbal (2000). Colonialidad del Poder, Eurocentrismo y América Latina", pp. 201-245, en Edgardo Lander (Ed) La Colonialidad del Saber: Eurocentrismo y ciencias sociales - perspectivas latinoamericanas. Buenos Aires: CLACSO.

13.Saxe, J y Delgado G. (2004). Imperialismo y Banco Mundial en América Latina. Centro de investigación y desarrollo de la cultura cubana Juan Marinello. La Habana

14.Vásquez, Belin (2013). Educación decolonial liberadora. En Perspectivas. Revista de Historia, Geografía, Arte y Cultura. Año $1 \mathrm{~N}^{\circ} 2 /$ Julio 2013, pp. 177196.Universidad Nacional Experimental Rafael María Baralt. ISSN: 2343-6271. 


\section{REFERENCES CONSULTED}

1. Aponte, A (2008). Blospot A grain of corn dated February 27, 2008. Available at http://ungranodemaiz.blogspot.com/2008/02/conciencia-del-deber-social.html

2. National Assembly (1999). Constitution of the Bolivarian Republic of Venezuela. Official Gazette of the Bolivarian Republic of Venezuela, 36,860, December 30.

3. National Assembly (2010). Organic Law of the Communes. Official Gazette of the Bolivarian Republic of Venezuela No. 6.011, dated December 21, 2010.

4. Castro Gómez (2005). The hybris of the zero point. Science, race and illustration in New Granada. (1750-1816). Pontifical Javeriana University. Bogotá.

5. Contreras S and Calles, J. (2016). Justice another from cultural diversity and emerging popular power. In lustitia Socialies. Arbitrated Journal of Legal Sciences. Santa Ana de Coro. Venezuela. Available at http://fundacionkoinonia.com.ve/ojs/index.php/lustitia Socialis/article/view/28/19

6. De Souza, J. (2011). Towards the "day after the development". Pontifical University of Ecuador. 6. Hinkerlammert, F. (2008). On the reconstitution of critical thinking. In Revista Polis vol. 7 no 21, 2008 prolog, pages., 367-395. Editorial of the Bolivarian University of Chile.

7. García, L., García, J and Isea, J. (2017). Contributions of the new science to scientific thinking in the management area. Interdisciplinary Arbitrated Journal Koinonía, 11 (1), 76-87. Available at http://fundacionkoinonia.com.ve/ojs/index.php/revistakoinonia/article/view/16

8. Huanacuni, F. (2010). Western Paradigm and Native Indigenous Paradigm. In Latin America in movement, February 2010, № 452, pp. 17-22.

9. Hinkerlammert, F. (2008). On the reconstitution of critical thinking. In Revista Polis vol. $7 \mathrm{n}^{\circ}$ 21, 2008 prolog, pages, 367-395. Editorial of the Bolivarian University of Chile

10.Maldonado, N. (2007). On the coloniality of being, contributions to the development of a concept. In The decolonial turn: Reflections for an epistemic diversity beyond global capitalism / compilers Santiago Castro-Gómez and Ramón Grosfoguel. Century of Man Publishers; Central University, Institute of Contemporary Social Studies and Pontificia Universidad Javeriana, Instituto Pensar. Bogotá 
11.Parsons, W. (2007). Public Policies, An introduction to the theory and practice of public policy analysis. Flacso. Mexico.

12.Quijano, Aníbal (2000). Coloniality of Power, Eurocentrism and Latin America ", pp. 201-245, in Edgardo Lander (Ed) The Coloniality of Knowledge: Eurocentrism and social sciences - Latin American perspectives. Buenos Aires: CLACSO.

13.Saxe, J and Delgado G. (2004). Imperialism and the World Bank in Latin America. Center for research and development of Cuban culture Juan Marinello. Havana

14.Vásquez, Belin (2013). Decolonial liberating education. In Perspectives. Journal of History, Geography, Art and Culture. Year 1 No. 2 / July 2013, pp. 177-196. National Experimental University Rafael María Baralt. ISSN: 2343-6271 